\title{
Effects of Prenatal Exposure to Betamethasone and Indomethacin on the Glomerular Filtration Rate in the Preterm Infant
}

\author{
JOHN N. VAN DEN ANKER, WIM C. J. HOP, RONALD DE GROOT, BERT J. VAN DER \\ HEIJDEN, HENRIETTE M. BROERSE, JAN LINDEMANS, AND PIETER J. J. SAUER \\ Departments of Pediatrics [J.N.v.d.A., R.d.G., H.M.B., P.J.J.S.], Epidemiology and \\ Biostatistics [W.C.J.H.], and Clinical Chemistry [J.L.], Erasmus University and University \\ Hospital Rotterdam/Sophia Children's Hospital, Rotterdam, The Netherlands, and Department \\ of Pediatrics, Juliana Children's Hospital, The Hague, The Netherlands [B.J.v.d.H.]
}

\section{ABSTRACT}

The effects of gestational age (GA), body weight, and prenatal exposure to betamethasone and indomethacin on the glomerular filtration rate (GFR) on $\mathrm{d} 3$ of life in preterm infants were studied. GFR measurements were performed in 147 preterm infants with a GA between 23.4 and 37.0 wk by means of the continuous inulin infusion technique. Mean GFR values increased significantly with GA $(r=0.60, p<0.001)$ and with body weight $(r=0.44, p<0.001)$. Multivariate analysis indicated that GA was the most important determinant for this increase. Prenatal exposure to indomethacin resulted in significantly lower GFR values $(-0.15 \pm 0.03 \mathrm{~mL} / \mathrm{min}, p<0.001)$ at d 3 after birth. Prenatal administration of betamethasone and indomethacin significantly $(p<0.001)$ increased the GFR in comparison with exposure to indomethacin alone to levels not different than those seen in patients who were not prenatally exposed to betamethasone or indomethacin. GFR measurements were repeated in 40 preterm infants on $\mathrm{d} 10$ after birth. During this 7-d period, a significant increase in GFR values $(0.17 \pm 0.03 \mathrm{~mL} / \mathrm{min}, p<0.001)$ was detected. This postnatal increase in GFR values was independent of GA and was not influenced by prenatal exposure to betamethasone or indomethacin. We conclude that prenatal exposure to betamethasone or indomethacin exerts significant effects on the renal function of preterm infants in the first days of life. (Pediatr Res 36: 578-581, 1994)

\section{GA, gestational age}

\section{Abbreviations}

GFR, glomerular filtration rate

RDS, respiratory distress syndrome
Developmental changes in the GFR of preterm neonates have been the subject of many studies (1-7). Most reports indicated the presence of a GA-dependent increase in the GFR (1-6). In contrast, Aperia et al. (7) could not confirm these findings. Most studies included only a limited number of infants with a wide variation in postnatal age, and several different techniques were used to measure the GFR. Previous reports did not consider the possible effect of prenatal exposure to different drugs on these developmental changes of the GFR.

Betamethasone and indomethacin are potent drugs that are frequently used during pregnancy. Betamethasone is a synthetic glucocorticoid with a potency equivalent to dexamethasone. The drug is prescribed to pregnant women with an increased risk of preterm delivery before the $32 \mathrm{nd}$ wk of gestation. The objective of this treatment is

Received September 20, 1993; accepted July 1, 1994.

Correspondence: John N. van den Anker, M.D., Sophia Children's Hospital, Dr. Molewaterplein 60, 3015 GJ Rotterdam, The Netherlands.

Supported by a research grant from Glaxo B.V., The Netherlands. to accelerate maturation of the alveolar epithelium and stimulate synthesis of lipid and protein components of the pulmonary surfactant complex to prevent hyaline membrane disease. We hypothesized that prenatal exposure to betamethasone might accelerate the maturation of the GFR. Indomethacin is prescribed to inhibit preterm uterine contractions before the 32nd wk of gestation. Short-term exposure to indomethacin leads to a reduction of the GFR, whereas conflicting data exist about the effect on the GFR after long-term exposure (8-10). We therefore studied the effects of GA, birth weight, and prenatal exposure to betamethasone and indomethacin on the GFR in a large population of preterm infants on $\mathrm{d} 3$ and 10 of life.

\section{METHODS}

Patients. One hundred forty-seven preterm infants admitted to the neonatal intensive care unit of the Sophia Children's Hospital between October 1989 and October 1991 were included in this study. Eighty-seven infants were male and 60 were female. Infants who were born in 
our hospital at less than $37 \mathrm{wk}$ of gestation were eligible for inclusion. The infants were hemodynamically stable (diuresis $>1 \mathrm{~mL} / \mathrm{kg} / \mathrm{h}$; systolic and diastolic blood pressure above the third percentile adjusted for GA), had normal liver function, had not received inotropic or nephrotoxic drugs, did not have an intracranial hemorrhage beyond grade II, and had an indwelling arterial catheter. The $\mathrm{PO}_{2}$ in arterial blood was kept at greater than $50 \mathrm{~mm}$ $\mathrm{Hg}$ or oxygen saturation greater than $92 \%$, and hematocrit values were maintained above 0.35 by packed erythrocyte transfusions. Infants were excluded from the study if they had life-threatening illnesses or became hemodynamically unstable (systolic and diastolic blood pressure below the third percentile adjusted for GA; diuresis $<1 \mathrm{~mL} / \mathrm{kg} / \mathrm{h}$ ). The study protocol was approved by the Medical Ethical Committee of the University Hospital Rotterdam. Patients were only enrolled after informed consent was obtained from the parents.

The GA of the 147 children was estimated from the mother's menstrual history, early ultrasound examinations if available, and physical examination using the criteria of Dubowitz et al. (11). Ninety-four children were not prenatally exposed to betamethasone or indomethacin (group A). Twenty-six children were prenatally exposed to indomethacin but not to betamethasone (group B). Only six children were prenatally exposed to betamethasone, but not to indomethacin (group C). Twenty-one children were prenatally exposed to both betamethasone and indomethacin (group D). Betamethasone had been administered in two i.v. doses of $12 \mathrm{mg}$ each on 2 consecutive days. This dose was repeated every week until delivery or until the $32 \mathrm{nd}$ wk of gestation. Indomethacin had been administered in suppositories of $100 \mathrm{mg}$ each, which were repeatedly given in the presence of preterm uterine contractions. In 40 infants, GFR measurements were repeated at d 10 after birth. Eighteen children were not prenatally exposed to betamethasone or indomethacin (group A). Thirteen children were prenatally exposed to indomethacin but not to betamethasone (group B). Two children were prenatally exposed to betamethasone, but not to indomethacin (group C). Seven children were prenatally exposed to both betamethasone and indomethacin (group D).

Laboratory studies. GFR values were determined by means of the continuous inulin infusion technique on the third day of life $(5,6,12)$. Inulin was obtained from Laevosan Gesellschaft mbH (Lienz, Austria) and was administered as a solution containing $25 \mathrm{~g}$ inulin/ $\mathrm{L}$ at an infusion rate of $0.6 \mathrm{~mL} / \mathrm{kg} / \mathrm{h}$. After $24 \mathrm{~h}$, the inulin clearance $\left(\mathrm{CL}_{\text {in }}\right)$ was calculated from the infusion rate $(R)$, the inulin concentration in the infusate (I), and the serum inulin concentration $\left(\mathrm{P}_{\text {in }}\right)$ with the following equation: $\mathrm{CL}_{\text {in }}=\mathrm{I} \cdot \mathrm{R} / \mathrm{P}_{\mathrm{in}}$. The determination of inulin in serum was performed after acid hydrolysis in $0.3 \mathrm{mmol} / \mathrm{L}$ perchloric acid for $15 \mathrm{~min}$ at $70^{\circ} \mathrm{C}$. The fructose thus formed was measured enzymatically according to Beutler (13).

Statistical analysis. Data given are mean \pm SEM unless indicated otherwise. Correlation coefficients given are Pearson's. Comparison of groups was done using the $t$ test. Multiple regression was used to evaluate various factors simultaneously with respect to GFR. $p$ values < 0.05 (two-tailed) were considered significant.

\section{RESULTS}

The GA of the 147 preterm infants varied between 23.4 and $37 \mathrm{wk}$ (mean $30.2 \mathrm{wk}$ ). The birth weight was between 560 and $3685 \mathrm{~g}$ (mean $1425 \mathrm{~g}$ ). One hundred thirty (88\%) of the children were appropriate for gestational age. One hundred seven $(73 \%)$ were ventilated at $\mathrm{d} 3$. GFR values at d 3 after birth ranged from 0.45 to $1.30 \mathrm{~mL} / \mathrm{min}$ (mean 0.85 $\mathrm{mL} / \mathrm{min})$. GFR values increased significantly with $\mathrm{GA}(r=$ $0.60, p<0.001)$. Multiple regression analysis showed the presence of a significant correlation between GFR and GA $(p<0.001)$. The percentage of explained variation of GFR considering only GA was $35.6 \%$. Body weight did not exert a significant effect on the GFR $(p=0.21)$. Artificial ventilation $(p=0.50)$, RDS ( $p=0.93)$, or small weight for GA $(p=0.33)$ also did not have a significant effect.

Timing before birth and cumulative dose of both indomethacin and betamethasone were analyzed. The median dose of indomethacin was $200 \mathrm{mg}$ (range 100-2200 mg). The median dose of betamethasone was $24 \mathrm{mg}$ (range 24-120 mg). We could not detect an effect of the dose and timing before birth of both drugs given to the mother on the GFR values measured on $\mathrm{d} 3$ of life.

The neonates were divided into four groups. Ninety-four infants were not prenatally exposed to betamethasone or indomethacin (group A). Twenty-six children were prenatally exposed to indomethacin alone (group B). Six children were prenatally exposed to betamethasone alone (group C). Twenty-one children were prenatally exposed to both betamethasone and indomethacin (group D). Table 1

Table 1. Clinical parameters of study infants*

\begin{tabular}{|c|c|c|c|c|}
\hline & $\begin{array}{c}\text { Group A } \\
(n=94) \\
\text { (Indo -/Beta -) } \\
\end{array}$ & $\begin{array}{c}\text { Group B } \\
(n=26) \\
\text { (Indo +/Beta }-) \\
\end{array}$ & $\begin{array}{c}\text { Group C } \\
(n=6) \\
(\text { Indo }-/ \text { Beta }+)\end{array}$ & $\begin{array}{c}\text { Group D } \\
(n=21) \\
(\text { Indo }+/ \text { Beta }+) \\
\end{array}$ \\
\hline $\mathrm{GA}(w k)$ & $31.4 \dagger(2.7)$ & $28.9(2.3)$ & $30.4(2.0)$ & $29.2(1.3)$ \\
\hline Weight (g) & $1534 \dagger(592)$ & $1156(349)$ & $1093(266)$ & $1174(265)$ \\
\hline AGA & $79(84 \%)$ & $25(96 \%)$ & $5(83 \%)$ & $21(100 \%)$ \\
\hline Ventilation & $73(78 \%)$ & $17(65 \%)$ & $3(50 \%)$ & $14(67 \%)$ \\
\hline RDS & $28(30 \%)$ & $5(19 \%)$ & $2(33 \%)$ & $4(19 \%)$ \\
\hline
\end{tabular}

* Values are mean $( \pm \mathrm{SD})$ or numbers $(\%)$ of patients. Indo, indomethacin; Beta, betamethasone; AGA, appropriate for gestational age. Symbols: - , no prenatal exposure; + , prenatal exposure.

$\dagger$ Significantly different $(p<0.005)$ from group B and D. 
Table 2. GFR values at $d 3$ after birth according to prenatal exposure to Beta, Indo, or both*

\begin{tabular}{|c|c|c|c|c|}
\hline & $\begin{array}{c}\text { Group A } \\
(n=94) \\
(\text { Indo }-/ \text { Beta }-)\end{array}$ & $\begin{array}{c}\text { Group B } \\
(n=26) \\
(\text { Indo }+/ \text { Beta }-)\end{array}$ & $\begin{array}{c}\text { Group C } \\
(n=6) \\
(\text { Indo }-/ \text { Beta }+)\end{array}$ & $\begin{array}{c}\text { Group D } \\
(n=21) \\
(\text { Indo }+/ \text { Beta }+)\end{array}$ \\
\hline $\mathrm{GFR}(\mathrm{mL} / \mathrm{min})$ & $0.91 \pm 0.02$ & $\begin{array}{c}0.66 \pm 0.02 \\
(-0.17 \pm 0.03) \dagger\end{array}$ & $\begin{aligned} 0.93 & \pm 0.06 \\
(0.05 & \pm 0.06) \dagger\end{aligned}$ & $\begin{aligned} 0.81 & \pm 0.03 \\
(-0.02 & \pm 0.04) \dagger\end{aligned}$ \\
\hline
\end{tabular}

* Values are mean \pm SEM. Indo, indomethacin; Beta, betamethasone. Symbols: - , no prenatal exposure; + , prenatal exposure.

$\dagger$ The GFR values given between parentheses represent the difference between the GFR in group A and the GA-adjusted GFR values in groups $B, C$, and D.

shows the clinical parameters including GA, birth weight, and percentage of children who were appropriate for gestational age, ventilated, or had RDS. The GA of children who were prenatally exposed to indomethacin with or without betamethasone (groups B and D) was significantly lower compared with the GA of the infants who were not prenatally exposed to betamethasone or indomethacin (group A). Table 2 delineates the relation between GA and GFR on d 3 of life after prenatal exposure to different combinations of betamethasone and indomethacin. After adjustment for the difference in GA between groups, the GFR values of the patients in group B (only prenatal exposure to indomethacin) were still significantly lower $(-0.17 \pm 0.03 \mathrm{~mL} / \mathrm{min}, p<0.001)$ compared with the GFR values of the patients in group A (not exposed to indomethacin or betamethasone). No significant difference was present between the GA-adjusted GFR values of the patients in group $\mathrm{D}$ (prenatal exposure to both betamethasone and indomethacin) and group A (not exposed to indomethacin or betamethasone). GA-adjusted GFR values of the patients in group D (prenatal exposure to both betamethasone and indomethacin) were significantly higher $(+0.15 \pm$ $0.04 \mathrm{~mL} / \mathrm{min}, p<0.001$ ) compared with the GA-adjusted GFR values of the infants in group B (prenatal exposure to indomethacin alone). A multivariate analysis was performed to analyze the impact of prenatal exposure to betamethasone and indomethacin on GFR values at $d 3$. Indomethacin use was associated with significantly lower $(-0.15 \pm 0.03 \mathrm{~mL} / \mathrm{min}, p<0.001)$ GFR values, whereas betamethasone use was associated with significantly higher $(+0.11 \pm 0.03 \mathrm{~mL} / \mathrm{min}, p<0.001)$ GFR values (Table 3$)$.

At d 10 after birth, GFR measurements were repeated in 40 children. During this 7 -d period, a significant increase in GFR values $(0.17 \pm 0.03 \mathrm{~mL} / \mathrm{min}, p<0.001)$ to normal levels was detected. This postnatal increase in GFR values was independent of GA and was not influenced by prenatal exposure to betamethasone or indomethacin.

Table 3. Effect of $G A$ and prenatal exposure to betamethasone or indomethacin on GFR values at 33 after birth*

\begin{tabular}{lcc}
\hline & Regression coefficient & $p$ value \\
\hline GA (wk) & $+0.035( \pm 0.005) \mathrm{mL} / \mathrm{min} / \mathrm{wk}$ & $<0.001$ \\
Indomethacin $\dagger$ & $-0.15( \pm 0.03) \mathrm{mL} / \mathrm{min}$ & $<0.001$ \\
Betamethasone $\dagger$ & $+0.11( \pm 0.03) \mathrm{mL} / \mathrm{min}$ & $<0.001$ \\
\hline$*$ Values are mean increase $( \pm \mathrm{SEM})$ & \\
$\dagger$ Prenatal exposure vs no prenatal exposure.
\end{tabular}

\section{DISCUSSION}

The data presented in this paper demonstrate the presence of a GA-dependent increase of the GFR in preterm infants. These findings are consistent with the results of most previous reports (1-6). The increase of the GFR was also associated with an increase in body weight. However, multivariate analysis showed that GA but not body weight was the major determinant for the development of the GFR. Our results do not support the presence of a significant effect of clinical variables such as artificial ventilation, RDS, and small size for gestational age on the development of the GFR. This is in accordance with some published studies $(6,14)$. However, other studies showed a marked decrease in GFR in infants with RDS $(15,16)$. Our patients were hemodynamically stable (diuresis $>1 \mathrm{~mL} / \mathrm{kg} / \mathrm{h}$; systolic and diastolic blood pressure above the third percentile adjusted for GA) and had no hypoxemia or hypercapnia. The lack of hypoxemia and especially hypercarbia in our patients probably explains our findings, indicating that RDS itself does not downregulate GFR, but perhaps hypoxemia or hypercarbia does.

In this study, most pregnant women who were treated with betamethasone were also treated with indomethacin to inhibit preterm uterine contractions. The number of patients exposed to betamethasone only was therefore too small for us to do a separate analysis. However, our analysis indicates that the GA-adjusted GFR of the children who were prenatally exposed to both betamethasone and indomethacin was significantly higher compared with the GFR of the children who were prenatally exposed to indomethacin alone. In addition, the GAadjusted GFR values of the children who were prenatally exposed to both drugs were not different from the GFR values of the children who were not exposed at all (group A). The use of multivariate analysis allowed us to detect an association between prenatal exposure to betamethasone and GFR values, showing significantly higher GFR values $(+0.11 \pm 0.03 \mathrm{~mL} / \mathrm{min})$ at $\mathrm{d} 3$ after birth after prenatal exposure to betamethasone. The effect of prenatal exposure to betamethasone on the development of the GFR at $\mathrm{d} 3$ was independent of the GA and could no longer be detected at d 10 after birth. The effects of exposure to betamethasone on the GFR have also been studied in several animal models. These studies suggested that administration of glucocorticoids results either in an increase in renal blood flow or in direct vaso- 
dilation of the renal vasculature $(17,18)$. Baylis and Brenner (19) provided evidence in a carefully delineated micropuncture study that values for single-nephron GFR were $25 \%$ higher in rats treated with methylprednisolone. Values for glomerular plasma flow rate were also $25 \%$ higher in the treatment group, whereas values of the transglomerular hydraulic pressure difference, afferent and efferent oncotic pressures, and filtration pressure equilibrium were similar between control animals and rats treated with methylprednisolone. These results indicated that the rise in single-nephron GFR was entirely due to an increase in glomerular plasma flow probably mediated by renal arteriolar vasodilation.

The effects of prenatal exposure to betamethasone on the GFR of preterm infants have been studied by three groups (20-22). These studies did not show an increase of the GFR during the first week of life after prenatal exposure to glucocorticoids. However, in these three studies, creatinine clearance was used as a less reliable marker for the GFR in preterm infants and a small number of children were studied. This might have prevented the authors from demonstrating an increase in the GFR in the first week of life after prenatal exposure to glucocorticoids. We hypothesize that prenatal exposure to betamethasone may lead to a direct vasodilating effect of the renal arterioles in preterm infants, which is probably mediated by glucocorticoid receptors.

Prenatal exposure to indomethacin resulted in significantly lower GFR values $(-0.15 \pm 0.03 \mathrm{~mL} / \mathrm{min})$ at $\mathrm{d} 3$ of life. This effect was independent of the cumulative dose of indomethacin given to the pregnant women, although $94 \%$ had received indomethacin within a period of $48 \mathrm{~h}$ before delivery. This effect of prenatal exposure to indomethacin on the development of the GFR at d 3 was independent of the GA and could no longer be detected at d 10 after birth. Animal studies have indicated that the inhibition of prostaglandin synthesis by indomethacin increases renal vascular resistance. This subsequently results in an impaired renal blood flow and a concomitant reduction in the GFR (23). This holds also for short-term exposure in the human neonate. Some case reports show that prolonged prenatal use of indomethacin can lead to deleterious renal and extrarenal effects $(8,9,24-26)$, whereas other reports could not detect any serious side effects $(10,27)$.

In summary, prenatal exposure to indomethacin significantly reduces GFR values at $\mathrm{d} 3$ after birth. Betamethasone significantly increases GFR when coadministered prenatally with indomethacin. Our data suggest that betamethasone increases the GFR irrespective of the use of indomethacin. Some authors previously showed that prenatal exposure to indomethacin may lead to a decrease in GFR. However, we could not demonstrate a decrease in GFR when both drugs were given simultaneously. We suggest that an increase in renal plasma flow due to betamethasone may overcome intrarenal vasoconstric- tion secondary to the decreased synthesis of intrarenal prostaglandins by indomethacin. Additional studies are needed to delineate the proposed effects of both drugs.

Acknowledgments. The authors thank Jean-Pierre Guignard and Herman J. Neijens for kindly reviewing this manuscript and Joke Ambagtsheer for performing the inulin assays.

\section{REFERENCES}

1. Al-Dahan J, Haycock GH, Chantler C, Stimmier L 1983 Sodium homeostasis in term and preterm neonates. I. Renal aspects. Arch Dis Child 58:335-342

2. Arant Jr BS 1978 Developmental patterns of renal functional maturation compared in the human neonate. $J$ Pediatr 92:705-712

3. Coulthard MG 1985 Maturation of glomerular filtration in preterm and mature babies. Early Hum Dev 11:281-292

4. Guignard JP, Torrado A, Da Cunha O, Gautier E 1975 Glomerular filtration rate in the first three weeks of life. J Pediatr 87:268-272

5. Leake RD, Trygstad CW, Oh W 1976 Inulin clearance in the newborn infant: relationship to gestational and postnatal age. Pediatr Res 10:759-762

6. Van der Heijden AJ, Grose WFA, Ambagtsheer JJ, Provoost AP, Wolff ED, Sauer PJJ 1988 Glomerular filtration rate in the preterm infant: the relation to gestational and postnatal age. Eur J Pediatr 148:24-28

7. Aperia A, Broberger O, Elinder G, Herin P, Zetterstrom R 1981 Postnatal development of renal function in pre-term and full-term infants. Acta Paediatr Scand 70:183-187

8. Van der Heijden AJ, Provoost AP, Nauta J, Grose W, Oranje WA, Wolff ED, Sauer PJJ 1988 Renal functional impairment in preterm neonates related to intrauterine indomethacin exposure. Pediatr Res 24:644-648

9. Dudley DKL, Hardie MJ 1985 Fetal and neonatal effects of indomethacin used as a tocolytic agent. Am J Obstet Gynecol 151:181-184

10. Wurtzel D 1990 Prenatal administration of indomethacin as a tocolytic agent: effect on neonatal renal function. Obstet Gynecol 76:689-692

11. Dubowitz LMS, Dubowitz V, Goldberg C 1970 Clinical assessment of gestational age in the newborn infant. J Pediatr 77:1-10

12. Coulthard MG, Ruddock V 1983 Validation of inulin as a marker for glomerular filtration in preterm babies. Kidney Int 23:407-409

13. Beutler H-O 1984 Inulin. In: Bergmeyer HU (ed) Methods of Enzymatic Analysis, Vol VI. Verlag Chemie, Weinheim, Germany, pp 41-45

14. Siegel SR, Fisher DA, Oh W 1973 Renal function and serum aldosterone levels in infants with respiratory distress syndrome. J Pediatr 83:854-856

15. Guignard JP, Torrado A, Mazouni SM, Gautier E 1976 Renal function in respiratory distress syndrome. J Pediatr 88:845-847

16. Tulassay T, Ritvay J, Bors Z, Buky B 1979 Alterations in creatinine clearance during respiratory distress syndrome. Biol Neonate 35:258-263

17. Davis JO, Howell DS 1953 Comparative effect of ACTH, cortisone and DCA on renal function, electrolyte excretion and water exchange in normal dogs. Endocrinology 52:245-255

18. De Bermudez L, Hayslett JP 1972 Effect of methylprednisolone on renal function and the zonal distribution of blood flow in the rat. Circ Res 31:44-52

19. Baylis C, Brenner BM 1978 Mechanism of the glucocorticoid-induced increase in glomerular filtration rate. Am J Physiol 234:F166-F170

20. MacKintosh D, Baird-Lambert J, Drage D, Buchanan N 1985 Effects of prenatal glucocorticoids on renal maturation in newborn infants. Dev Pharmacol Ther 8:107-114

21. Al-Dahan J, Stimmler L, Chantler C, Haycock GB 1987 The effect of antenatal dexamethasone administration on glomerular filtration rate and renal sodium excretion in premature infants. Pediatr Nephrol 1:131-135

22. Zanardo V, Giacobbo F, Zambon P, Trevisamito D, Griffith P, Grella P, Zachello G 1990 Antenatal aminophylline and steroid exposure: effects on glomerular filtration rate and renal sodium excretion in preterm newborns. J Perinat Med 18:283-288

23. Duarte-Silva M, Gouyon JB, Guignard JP 1986 Renal effects of indomethacin and dopamine in newborn rabbits. Kidney Int 30:453-459

24. Vanhaesebrouck $P$, Thiery M, Leroy JC, Govaert P, de Praeter C, Coppens M, Cuvelier C, Dhont M 1988 Oligohydramnion, renal insufficiency and ileal perforation in preterm infants after intrauterine exposure to indomethacin. $J$ Pediatr 145:738-743

25. Veersema D, De Jong PA, Van Wijck JAM 1983 Indomethacin and the fetal nonfunction syndrome. Eur J Obstet Gynaecol Reprod Biol 16:113-121

26. Simeoni U, Messer J, Weisburd P, Haddad J, Willard D 1989 Neonatal renal dysfunction and intrauterine exposure to prostaglandin synthesis inhibitors. Eur J Pediatr 148:371-373

27. Gerson A, Abassi S, Johnson A, Kalchbrenner MN, Asmead G, Bolognese R 1990 Safety and efficacy of long-term tocolysis with indomethacin. Am J Perinatol 7:74-84 